NASA/TM-2007-214468

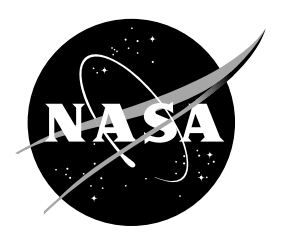

\title{
Wear Behavior of Low-Cost, Lightweight TiC/Ti-6Al-4V Composite Under Fretting: Effectiveness of Solid-Film Lubricant Counterparts
}

Kazuhisa Miyoshi and Kenneth W. Street, Jr.

Glenn Research Center, Cleveland, Ohio

Jeffrey H. Sanders, Carl H. Hager, Jr., and Jeffrey S. Zabinski

Air Force Research Laboratory, Wright-Patterson Air Force Base, Dayton, Ohio

Randall L. Vander Wal

National Center for Space Exploration Research, Cleveland, Ohio

Rodney Andrews

University of Kentucky, Lexington, Kentucky

Bradley A. Lerch

Glenn Research Center, Cleveland, Ohio 


\section{NASA STI Program . . . in Profile}

Since its founding, NASA has been dedicated to the advancement of aeronautics and space science. The NASA Scientific and Technical Information (STI) program plays a key part in helping NASA maintain this important role.

The NASA STI Program operates under the auspices of the Agency Chief Information Officer. It collects, organizes, provides for archiving, and disseminates NASA's STI. The NASA STI program provides access to the NASA Aeronautics and Space Database and its public interface, the NASA Technical Reports Server, thus providing one of the largest collections of aeronautical and space science STI in the world. Results are published in both non-NASA channels and by NASA in the NASA STI Report Series, which includes the following report types:

- TECHNICAL PUBLICATION. Reports of completed research or a major significant phase of research that present the results of NASA programs and include extensive data or theoretical analysis. Includes compilations of significant scientific and technical data and information deemed to be of continuing reference value. NASA counterpart of peer-reviewed formal professional papers but has less stringent limitations on manuscript length and extent of graphic presentations.

- TECHNICAL MEMORANDUM. Scientific and technical findings that are preliminary or of specialized interest, e.g., quick release reports, working papers, and bibliographies that contain minimal annotation. Does not contain extensive analysis.

- CONTRACTOR REPORT. Scientific and technical findings by NASA-sponsored contractors and grantees.
- CONFERENCE PUBLICATION. Collected papers from scientific and technical conferences, symposia, seminars, or other meetings sponsored or cosponsored by NASA.

- SPECIAL PUBLICATION. Scientific, technical, or historical information from NASA programs, projects, and missions, often concerned with subjects having substantial public interest.

- TECHNICAL TRANSLATION. Englishlanguage translations of foreign scientific and technical material pertinent to NASA's mission.

Specialized services also include creating custom thesauri, building customized databases, organizing and publishing research results.

For more information about the NASA STI program, see the following:

- Access the NASA STI program home page at http://www.sti.nasa.gov

- E-mail your question via the Internet to help@sti.nasa.gov

- Fax your question to the NASA STI Help Desk at 301-621-0134

- Telephone the NASA STI Help Desk at 301-621-0390

- Write to: NASA Center for AeroSpace Information (CASI) 7115 Standard Drive Hanover, MD 21076-1320 
NASA/TM-2007-214468

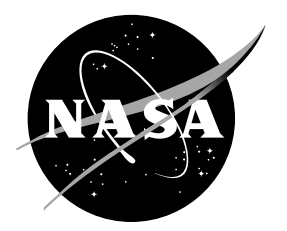

\section{Wear Behavior of Low-Cost, Lightweight TiC/Ti-6Al-4V Composite Under Fretting: Effectiveness of Solid-Film Lubricant Counterparts}

Kazuhisa Miyoshi and Kenneth W. Street, Jr.

Glenn Research Center, Cleveland, Ohio

Jeffrey H. Sanders, Carl H. Hager, Jr., and Jeffrey S. Zabinski

Air Force Research Laboratory, Wright-Patterson Air Force Base, Dayton, Ohio

Randall L. Vander Wal

National Center for Space Exploration Research, Cleveland, Ohio

Rodney Andrews

University of Kentucky, Lexington, Kentucky

Bradley A. Lerch

Glenn Research Center, Cleveland, Ohio

National Aeronautics and

Space Administration

Glenn Research Center

Cleveland, Ohio 44135 


\section{Acknowledgments}

This work was supported by the NASA ESR\&T_-ASTP MTLAMP project (the NASA Supersonic Research Project) and the NASA Vehicle Systems program's Low Emissions Alternate Power project, Alternate Fuels Foundation Technologies in Aeronautics Research through the Nanotechnology-Lubrication task at the NASA Glenn Research Center. The authors gratefully acknowledge Aaron J. Tomasek, Gordon M. Berger, and Richard J. Mondry II for assistance with the experiments; David R. Hull for the HRTEM; and Duane J. Dixon for the SEM.

This report is a formal draft or working paper, intended to solicit comments and ideas from a technical peer group.

This work was sponsored by the Fundamental Aeronautics Program at the NASA Glenn Research Center.

Level of Review: This material has been technically reviewed by technical management.

Available from

NASA Center for Aerospace Information 7115 Standard Drive

Hanover, MD 21076-1320
National Technical Information Service 5285 Port Royal Road Springfield, VA 22161 


\title{
Wear Behavior of Low-Cost, Lightweight TiC/Ti-6Al-4V Composite Under Fretting: Effectiveness of Solid-Film Lubricant Counterparts
}

\author{
Kazuhisa Miyoshi and Kenneth W. Street, Jr. \\ National Aeronautics and Space Administration \\ Glenn Research Center \\ Cleveland, Ohio 44135 \\ Jeffrey H. Sanders, Carl H. Hager, Jr., and Jeffrey S. Zabinski \\ Air Force Research Laboratory \\ Wright-Patterson Air Force Base \\ Dayton, Ohio 45433 \\ Randall L. Vander Wal \\ National Center for Space Exploration Research \\ Cleveland, Ohio 44135 \\ Rodney Andrews \\ University of Kentucky \\ Lexington, Kentucky 40511 \\ Bradley A. Lerch \\ National Aeronautics and Space Administration \\ Glenn Research Center \\ Cleveland, Ohio 44135
}

\begin{abstract}
Summary
The wear behavior of low-cost, lightweight 10 -wt $\%$ TiC-particulate-reinforced Ti-6Al-4V matrix composite (TiC/Ti-6Al-4V) was examined under fretting at 296, 423, and $523 \mathrm{~K}$ in air. Bare $10-\mathrm{wt} \%$ $\mathrm{TiC} / \mathrm{Ti}-6 \mathrm{Al}-4 \mathrm{~V}$ hemispherical pins were used in contact with dispersed multiwalled carbon nanotubes (MWNTs), magnetron-sputtered diamondlike carbon/chromium (DLC/Cr), magnetron-sputtered graphitelike carbon/chromium (GLC/Cr), and magnetron-sputtered molybdenum disulphide/titanium $\left(\mathrm{MoS}_{2} / \mathrm{Ti}\right)$ deposited on Ti-6Al-4V, Ti-48Al-2Cr-2Nb, and nickel-based superalloy 718 . When TiC/Ti$6 \mathrm{Al}-4 \mathrm{~V}$ was brought into contact with bare Ti-6Al-4V, bare Ti-48Al-2Cr-2Nb, and bare nickel-based superalloy 718, strong adhesion, severe galling, and severe wear occurred. However, when TiC/Ti-6Al$4 \mathrm{~V}$ was brought into contact with $\mathrm{MWNT}, \mathrm{DLC} / \mathrm{Cr}, \mathrm{GLC} / \mathrm{Cr}$, and $\mathrm{MoS}_{2} / \mathrm{Ti}$ coatings, no galling occurred in the contact, and relatively minor wear was observed regardless of the coating. All the MWNT, $\mathrm{DLC} / \mathrm{Cr}, \mathrm{GLC} / \mathrm{Cr}$, and $\mathrm{MoS}_{2} / \mathrm{Ti}$ coatings on Ti-6Al-4V were effective from 296 to $523 \mathrm{~K}$, but the effectiveness of the MWNT, DLC/Cr, GLC/Cr, and $\mathrm{MoS}_{2} / \mathrm{Ti}$ coatings decreased as temperature increased.
\end{abstract}

\section{Introduction}

Conventional titanium alloys typically display poor tribological properties because they are chemically active and exhibit strong adhesion when in contact with themselves and other materials (ref. 1). This adhesion causes high friction, and subsequently galling, which results in heavy surface damage in practical cases. The Galileo spacecraft's high-gain antenna deployment anomaly is an example: the titanium alloy component on the high-gain antenna was stuck on a counterpart superalloy component (ref. 1). 
Virtually all machines and components on a spacecraft vibrate and receive a great amount of relative motion due to shipping and the launching process. Fretting occurs in joints between components that are not intended to move. Vibrational wear of bulk materials and coatings may result from high contact pressure and cyclic motion (oscillatory tangential displacement) of small amplitude, and galling occurs in the contact. Another example has been found in aircraft. Fretting is a serious concern in a wide range of titanium alloy components used in aircraft engines because observations of service-exposed titaniumbased alloy fan blade-disk couples in fan engine propulsion systems revealed the presence of severe galling and fretting damage on the contacting surfaces of blade dovetails and disk slots (refs. 2 to 5). The performance of turbine blades is often limited by tribological fretting problems.

Ways to reduce fretting wear and fatigue damage in titanium alloys were studied with the introduction of diamondlike carbon (DLC) surface coatings to materials couples in contact and to titanium 48 -wt $\%$ aluminum 2-wt $\%$ chromium $2-w t \%$ niobium (Ti-48Al-2Cr-2Nb) crack-resistant alloy (refs. 6 to 12). The fretting wear characteristics of DLC and Ti-48Al-2Cr-2Nb have shown promising capabilities in reducing fretting wear and fatigue damage. The present investigation is continuing this effort and is seeking further improvements in the fretting characteristics of titanium alloys.

A titanium carbide (TiC) particulate-reinforced titanium 6 -wt $\%$ aluminum $4-w t \%$ vanadium (Ti-6Al-4V) composite is of great interest for further improving tribological properties, particularly wear resistance and crack resistance, in comparison to those of conventional monolithic Ti-6Al-4V alloy, because new manufacturing technologies can now produce uniformly distributed particle-strengthened titanium matrix composites (TMCs) at costs lower than for many types of continuous-fiber composites (refs. 13 to 17). The TMCs can be produced using particulate TiC as an addition to the powder metallurgy titanium-alloy matrix. The use of a TiC particulate permits the low-cost powder metallurgy manufacturing technology and fabrication process to be used. Furthermore, TiC is thermodynamically stable in the titanium-alloy matrix at processing temperatures. This leads to a stable particle-matrix interface and avoids the detrimental interactions that occur between titanium and stiffeners, such as silicon carbide particulates, in the process.

The 10-wt\% TiC-particulate-reinforced Ti-6Al-4V matrix composite (TiC/Ti-6Al-4V) has roomtemperature elastic modulus values that are about 15 percent higher on average than those of the monolithic Ti-6Al-4V alloy. Furthermore, the modulus advantage persists over the temperature range to $925 \mathrm{~K}$. Also, it was reported by the Ohio Aerospace Institute (OAI)-NASA group that the process results in near-final-shape components having a material stiffness up to 26-percent greater than that of components made with conventional titanium materials (ref. 16). This benefit is achieved with no significant increase in the weight of the component. In addition, the TMC material has good machinability.

The primary objective of this investigation is to study and evaluate the wear characteristics of the low-cost, lightweight $10-\mathrm{wt} \% \mathrm{TiC} / \mathrm{Ti}-6 \mathrm{Al}-4 \mathrm{~V}$ under fretting. Fretting experiments were conducted with polished bare $10-\mathrm{wt} \% \mathrm{TiC} / \mathrm{Ti}-6 \mathrm{Al}-4 \mathrm{~V}$ hemispherical pins in contact with polished, bare Ti-6Al-4V, Ti48Al-2Cr-2Nb, and nickel-based superalloy 718 disks at temperatures of 296, 423, and $523 \mathrm{~K}$ in air. Fretting experiments also were conducted with bare 10-wt\% TiC/Ti-6Al-4V hemispherical pins in contact with four types of solid-film lubricants at temperatures of 296, 423, and $523 \mathrm{~K}$ in air. The four solid-film lubricants were dispersed multiwalled carbon nanotubes (MWNTs), magnetron-sputtered diamondlike carbon/chromium (DLC/Cr), magnetron-sputtered graphitelike carbon/chromium (GLC/Cr), and magnetron-sputtered molybdenum disulphide/titanium $\left(\mathrm{MoS}_{2} / \mathrm{Ti}\right)$. All the solid-film lubricants were deposited on Ti-6Al-4V disk substrates. All fretting experiments were conducted at a load of $1.0 \mathrm{~N}$, a frequency of $80 \mathrm{~Hz}$, and a slip amplitude of $\sim 50 \mu \mathrm{m}$ for $1 \mathrm{hr}$. Analyses of as-received surfaces, wear surfaces, transfer films, wear debris, and microstructures were conducted using high-resolution transmission electron microscopy (HRTEM), scanning electron microscopy (SEM), energy-dispersive x-ray spectroscopy (EDS), optical microscopy, and noncontact, vertical-scanning-interferometry (VSI). 


\section{Materials}

The particulate titanium matrix composite (TiC/Ti-6Al-4V) fabricated by powder metallurgy consists of titanium alloy Ti-6Al-4V, as the matrix material, containing $10 \mathrm{wt} \%$ of ceramic TiC particles. A set of hemispherical pin specimens was manufactured from a sample of the $10-\mathrm{wt} \% \mathrm{TiC} / \mathrm{Ti}-6 \mathrm{Al}-4 \mathrm{~V}$ bars. All the pin specimens were polished with $3-\mu \mathrm{m}$-diameter diamond powder. Figure 1 shows distributed particle-strengthened titanium matrix composite. The mean value of Vickers microhardness of the composite at $296 \mathrm{~K}$ is 17-percent greater than that of the plain Ti-6Al-4V alloy (table I). This is expected because the ceramic particles increase stress and hardness in the matrix materials. The tensile strength of the composite is 14-percent greater than that of the plain Ti-6Al-4V.

A set of alloy flat-disk specimens was manufactured, and the surfaces that would be brought into contact with pins were polished with 3- $\mu$ m-diameter diamond powder. The ultimate tensile strengths of Ti-6Al-4V, Ti-48Al-2Cr-2Nb, and superalloy 718 are 950, 410, and $1434 \mathrm{MPa}$, respectively, at room temperature. Superalloy 718 is a precipitation-hardenable nickel-chromium alloy containing significant amounts of iron, niobium, and molybdenum along with lesser amounts of aluminum and titanium.
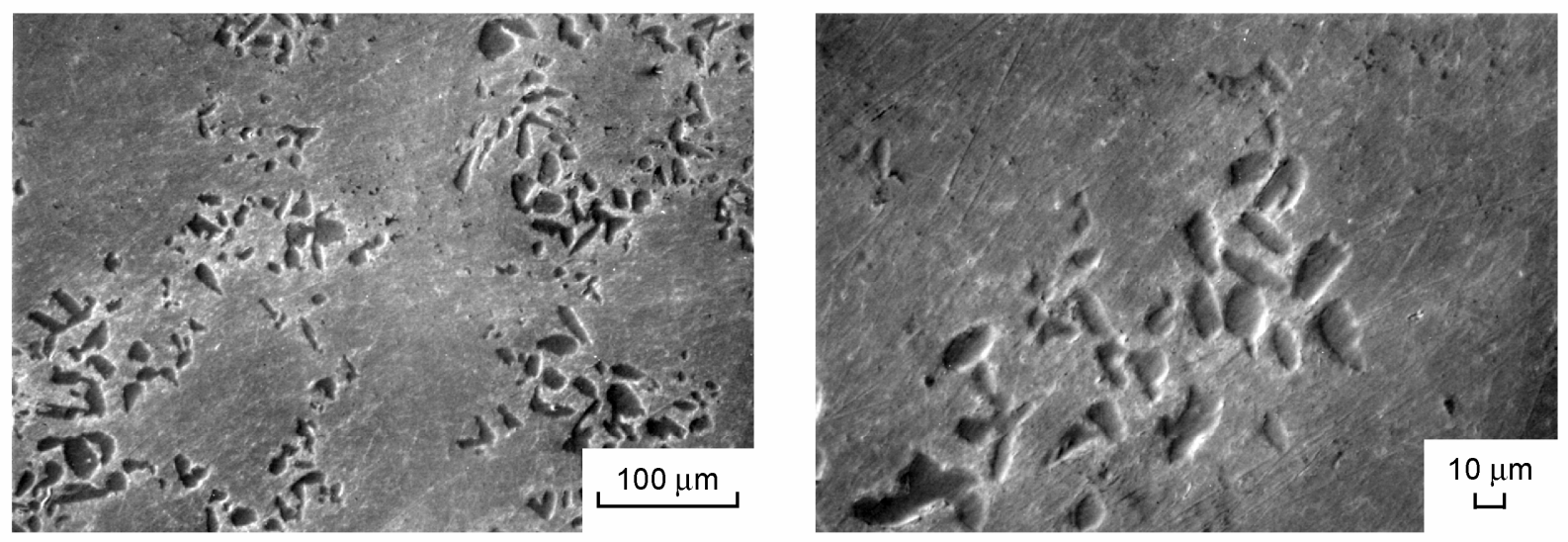

Figure 1.-Distribution of titanium carbide particles in a matrix of titanium alloy, Ti-6Al-4V.

TABLE I.-MATERIALS AND SOLID-FILM LUBRICANT COATINGS USED IN THIS INVESTIGATION AND THEIR SURFACE ROUGHNESS AND VICKERS MICROHARDNESS

\begin{tabular}{|l|c|c|c|c|}
\hline \multicolumn{1}{|c|}{ Specimen } & \multicolumn{2}{c|}{$\begin{array}{c}\text { Centerline-average roughness, } \\
R_{a}, \\
\end{array}$} & \multicolumn{2}{|c|}{$\begin{array}{c}\text { Vickers hardness, } \\
\text { nm (indentation load), } \\
\text { GPa }\end{array}$} \\
\cline { 2 - 5 } & Mean & $\begin{array}{c}\text { Standard } \\
\text { deviation }\end{array}$ & $\begin{array}{c}\text { Mean } \\
\text { Standard } \\
\text { deviation }\end{array}$ \\
\hline TiC/Ti-6Al-4V composite as-finished at 296 K & 225 & 76 & 3.65 & 0.42 \\
TiC directly interacted with indentations & & & 4.73 & .47 \\
Ti-6Al-4V matrix itself & & & 3.19 & .14 \\
TiC/Ti-6Al-4V composite heated to 823 K & $1.45 \times 10^{3}$ & $0.51 \times 10^{3}$ & 3.70 & .61 \\
Ti-6Al-4V as-finished at 296 K & 60 & 13 & 3.12 & .076 \\
Ti-6Al-4V heated to 823 K & $1.03 \times 10^{3}$ & $0.37 \times 10^{3}$ & 3.72 & .25 \\
Ti-48Al-2Cr-2Nb as-finished at 296 K & 35 & 3.3 & 3.78 & .57 \\
Nickel-base superalloy 718 as-finished at 296 K & 18 & 7.2 & 4.78 & .21 \\
DLC/Cr (2- $\mu$ m-thick coating) on Ti-6Al-4V & 84 & 13 & 11.3 & 2.3 \\
GLC/Cr (2.5- $\mu$ m-thick coating) on Ti-6Al-4V & 98 & 17 & 6.52 & 0.71 \\
MoS $/$ Ti (1- $\mu$ m-thick coating) on Ti-6Al-4V & 96 & 9.1 & 3.93 & .17 \\
Ti-6Al-4V substrate before deposition of dispersed MWNTs coating & 60 & 13 & 3.12 & .076 \\
\hline
\end{tabular}

${ }^{\mathrm{a}}$ The measurements of centerline-average roughness and Vickers microhardness were conducted with specimens exposed to $823 \mathrm{~K}$ in air. All measurements were, however, performed at $296 \mathrm{~K}$. 

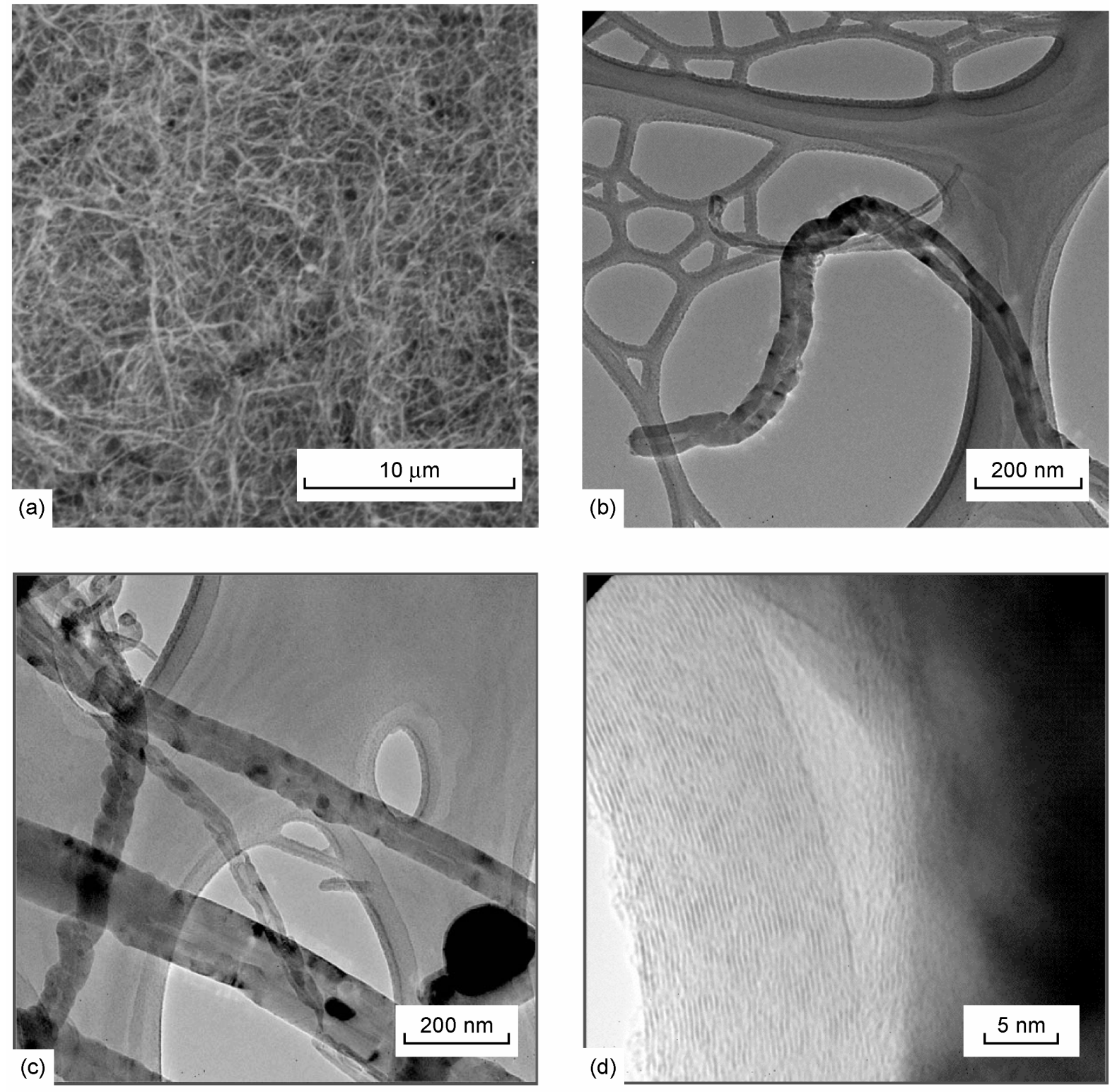

Figure 2.-Electron micrographs of multiwalled carbon nanotubes. (a) Low magnification (SEM). (b) Low magnification (TEM). (c) Low magnification (TEM). (d) High magnification (HRTEM).

The synthesis and dispersed-film preparation of MWNTs are described elsewhere (ref. 17). Since the MWNTs were agglomerated, a dilute solution of MWNT particles, nonionic surfactant, and solvent were placed in an ultrasonic bath prior to deposition of the MWNTs on the Ti-6Al-4V disk surface so that the MWNTs would have a proper suspension. The dispersed MWNT coating films were deposited on Ti-6Al$4 \mathrm{~V}$ disks with the dilute MWNT suspension, then the solvent was evaporated under dry nitrogen flow. MWNT coating films with a standard thickness of $2.52 \mu \mathrm{g}-\mathrm{mm}^{-2}$ were used. Figures 2(a) to (d) present an SEM micrograph and transmission electron microscopy (TEM) and HRTEM photomicrographs of MWNTs, showing a tangle of long, thin cylinders (randomly oriented tubular, nanofiberlike particles), multiwalled carbon nanotubes with different diameters, different inner channels, and a wall structure with some breaks and discontinuities among the carbon lamellae. 
The commercially available DLC/Cr, GLC/Cr, and $\mathrm{MoS}_{2} / \mathrm{Ti}$ coatings were deposited on Ti-6Al-4V disk substrates by magnetron sputtering at Teer Coatings LTD, Worcestershire, UK (ref. 18). Each coating had an interlayer for adhesion enhancement. DLC and GLC coatings had a $\sim 200-\mathrm{nm}$-thick $\mathrm{Cr}$ interlayer, and $\mathrm{MoS}_{2}$ coatings had a $\sim 100$-nm-thick Ti interlayer. During the DLC coating process, the plasma is radiofrequency enhanced. According to the manufacturer, the coating thicknesses of DLC/Cr, $\mathrm{GLC} / \mathrm{Cr}$, and $\mathrm{MoS}_{2} / \mathrm{Ti}$ were approximately $2,2.5$, and $1 \mu \mathrm{m}$, respectively.

\section{Experiments}

Figure 3 presents the high-temperature fretting wear apparatus used in this investigation. Fretting wear experiments were conducted with 3-mm-diameter, hemispherical TiC/Ti-6Al-4V composite pins in contact with the surfaces of the four types of solid-film lubricants in air at temperatures of 296, 423, and $523 \mathrm{~K}$. Also, fretting wear experiments were conducted with 3-mm-diameter, hemispherical TiC/Ti-6Al$4 \mathrm{~V}$ composite pins in contact with the bare, polished surfaces of the three types of alloy disks in air at temperatures of 296,423 , and $523 \mathrm{~K}$. All fretting wear experiments were conducted at a load of $1 \mathrm{~N}$, a frequency of $80 \mathrm{~Hz}$, and a slip-amplitude of $\sim 50 \mu \mathrm{m}$ for $2.88 \times 10^{5}$ cycles. In this investigation, shaft 1 (see fig. 3) was disconnected and shaft 2 was used for the $80-\mathrm{Hz}$ experiments.

Both the pin and disk surfaces were rinsed with 200-proof ethyl alcohol before installation in the fretting apparatus. Two or three fretting experiments were conducted with each material couple at each fretting condition. Then, the data were averaged to obtain the wear volume loss of material.

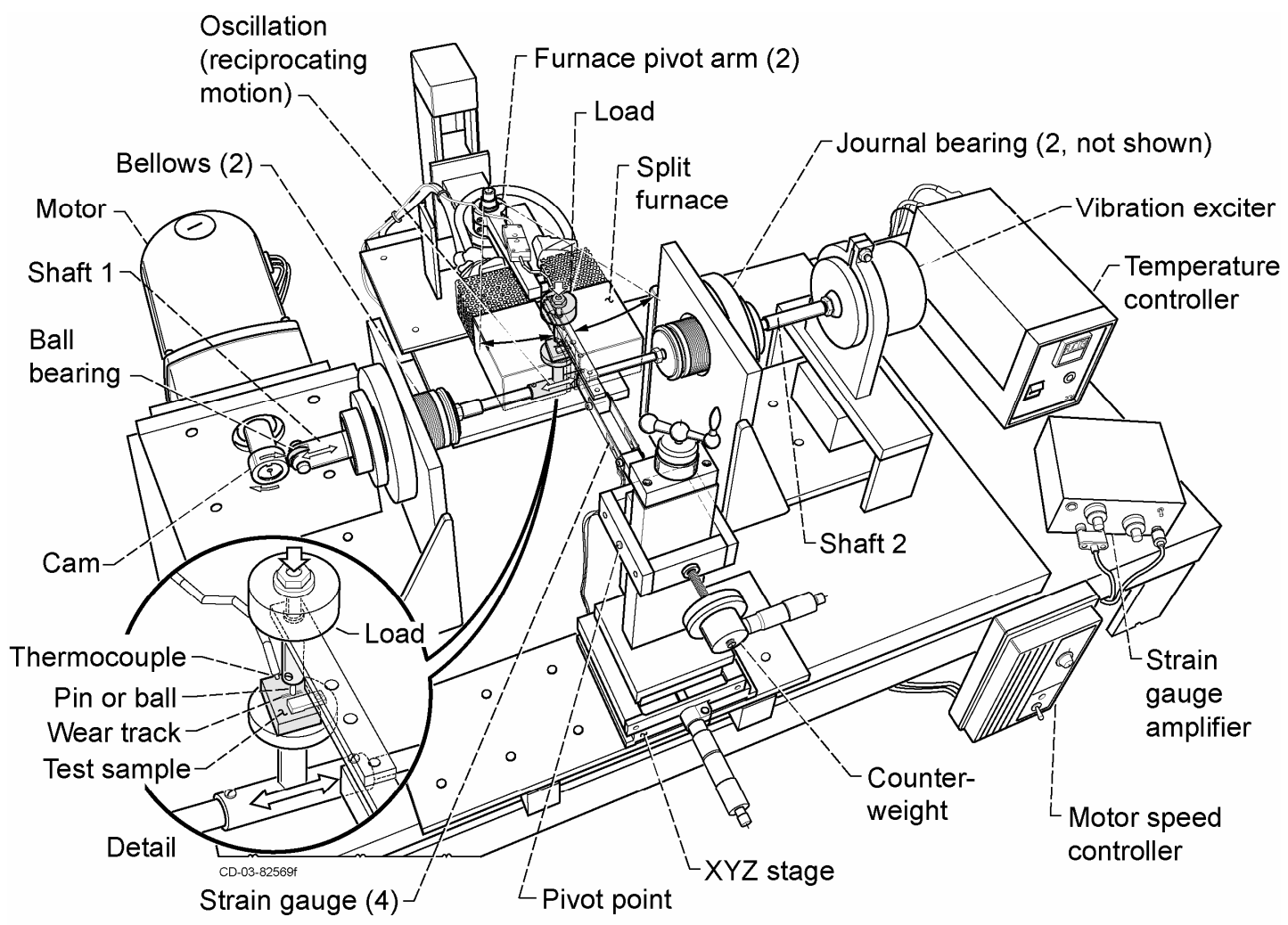

Figure 3.-High-temperature, reciprocating fretting/sliding friction apparatus. 
Analytical techniques (refs. 19 and 20) were used to characterize the surface chemistry, morphology, and topography of the pins and disks, including (1) HRTEM to characterize the nanostructure and microstructure; (2) VSI with a profile height resolution of $0.1 \mathrm{~nm}$ to determine surface characteristics, such as topography, roughness, and wear volume loss; (3) SEM with EDS and optical microscopy to determine the morphology and elemental composition of wear surfaces, transferred materials, and wear debris; and (4) Vickers hardness testing to determine the microhardness of the materials at $296 \mathrm{~K}$.

The surfaces of the disk specimens, determined by using VSI, were relatively smooth - having a centerline average roughness $R_{a}$ in the range 18 to $98 \mathrm{~nm}$ (table I) - compared with those of TiC/Ti-6Al$4 \mathrm{~V}$ composite pins. The wear volume loss of the pins and disks was determined by using VSI and/or SEM. The wear volume loss of a pin specimen was determined by measuring the size of the wear scar on the tip of the pin after an experiment. The diameters of the wear area were measured on an SEM photographic print using electronic digital calipers, SEM image analysis, and/or VSI image analysis. Then, the mean diameter of a nearly circular wear scar was used to calculate the volume of pin material that would have been removed. The wear volume loss of a disk specimen was determined by using VSI.

\section{Results}

\section{TiC/Ti-6Al-4V Fretted Against Ti-6Al-4V With and Without Solid-Film Lubricants}

Figures 4(a) and (b) show the specific wear rates of the pins and disks, respectively, obtained from fretting wear experiments in air at $296 \mathrm{~K}$ for bare composite TiC/Ti-6Al-4V pins in contact with different counterpart material disks: MWNTs on Ti-6Al-4V, DLC/Cr on Ti-6Al-4V, GLC/Cr on Ti-6Al-4V, $\mathrm{MoS}_{2} / \mathrm{Ti}$ on Ti-6Al-4V, and bare Ti-6Al-4V. They indicate that the wear rates of both the pins and disks for $\mathrm{TiC} / \mathrm{Ti}-6 \mathrm{Al}-4 \mathrm{~V}$ fretted against solid-film lubricants deposited on Ti-6Al-4V are much lower than those for TiC/Ti-6Al-4V fretted against bare Ti-6Al-4V. All the solid-film lubricant coatings dramatically improved the wear rate of TiC/Ti-6Al-4V pins. The MWNT coating reduced the TiC/Ti-6Al-4V pin wear rate so much that it was almost not measurable, and the wear rate for the pin at $296 \mathrm{~K}$ in air was around $3.3 \times 10^{-8} \mathrm{~mm}^{3} \cdot \mathrm{N}^{-1} \cdot \mathrm{m}^{-1}$. The wear rates of composite TiC/Ti-6Al-4V pins fretted against MWNT-, $\mathrm{DLC} / \mathrm{Cr}-, \mathrm{MoS}_{2} / \mathrm{Ti}$-, and GLC/Cr-coated Ti6Al-4V disks were two to three orders of magnitude lower than that fretted against bare Ti-6Al-4V (fig. 4(a)). For example, the wear rate of the pin fretted against DLC-coated Ti-6Al-4V was $9.8 \times 10^{-8} \mathrm{~mm}^{3} \cdot \mathrm{N}^{-1} \cdot \mathrm{m}^{-1}$, whereas that of the pin fretted against bare Ti-6Al-4V was $2.7 \times 10^{-5} \mathrm{~mm}^{3} \cdot \mathrm{N}^{-1} \cdot \mathrm{m}^{-1}$.

The wear of the dispersed MWNT coating was difficult to define and was not measured in this investigation because of the nature of the tangled, dispersed MWNTs (e.g., fig. 2). Almost no wear of the Ti-6Al-4V disk substrate was observed for the Ti-6Al-4V disk coated with MWNTs. Figure 4(b), therefore, shows (1) the wear rate of the Ti-6Al-4V substrate for MWNT-coated Ti-6Al-4V excluding the wear loss of the MWNTs and (2) the wear volume loss of DLC/Cr, $\mathrm{MoS}_{2} / \mathrm{Ti}$, and $\mathrm{GLC} / \mathrm{Cr}$ for DLC/Cr-, $\mathrm{MoS}_{2} / \mathrm{Ti}$-, and GLC/Cr-coated Ti-6Al-4V. The wear rates shown in fig. 4(b), therefore, should be viewed with caution. The wear rate of the Ti-6Al-4V substrate was almost not measurable (around $3.8 \times 10^{-8} \mathrm{~mm}^{3} \cdot \mathrm{N}^{-1} \cdot \mathrm{m}^{-1}$ ). The wear rates of MWNT-, DLC/Cr-, $\mathrm{MoS}_{2} / \mathrm{Ti}$-, and GLC/Cr-coated Ti-6Al-4V disks were one order to three orders of magnitude lower than that of bare Ti-6Al-4V (fig. 4(b)). For example, the wear rate of DLC/Cr fretted against the composite at $296 \mathrm{~K}$ was $8.5 \times 10^{-7} \mathrm{~mm}^{3} \cdot \mathrm{N}^{-1} \cdot \mathrm{m}^{-1}$, whereas that of the bare Ti-6Al-4V fretted against the composite at $296 \mathrm{~K}$ was $7.2 \times 10^{-5} \mathrm{~mm}^{3} \cdot \mathrm{N}^{-1} \cdot \mathrm{m}^{-1}$. 

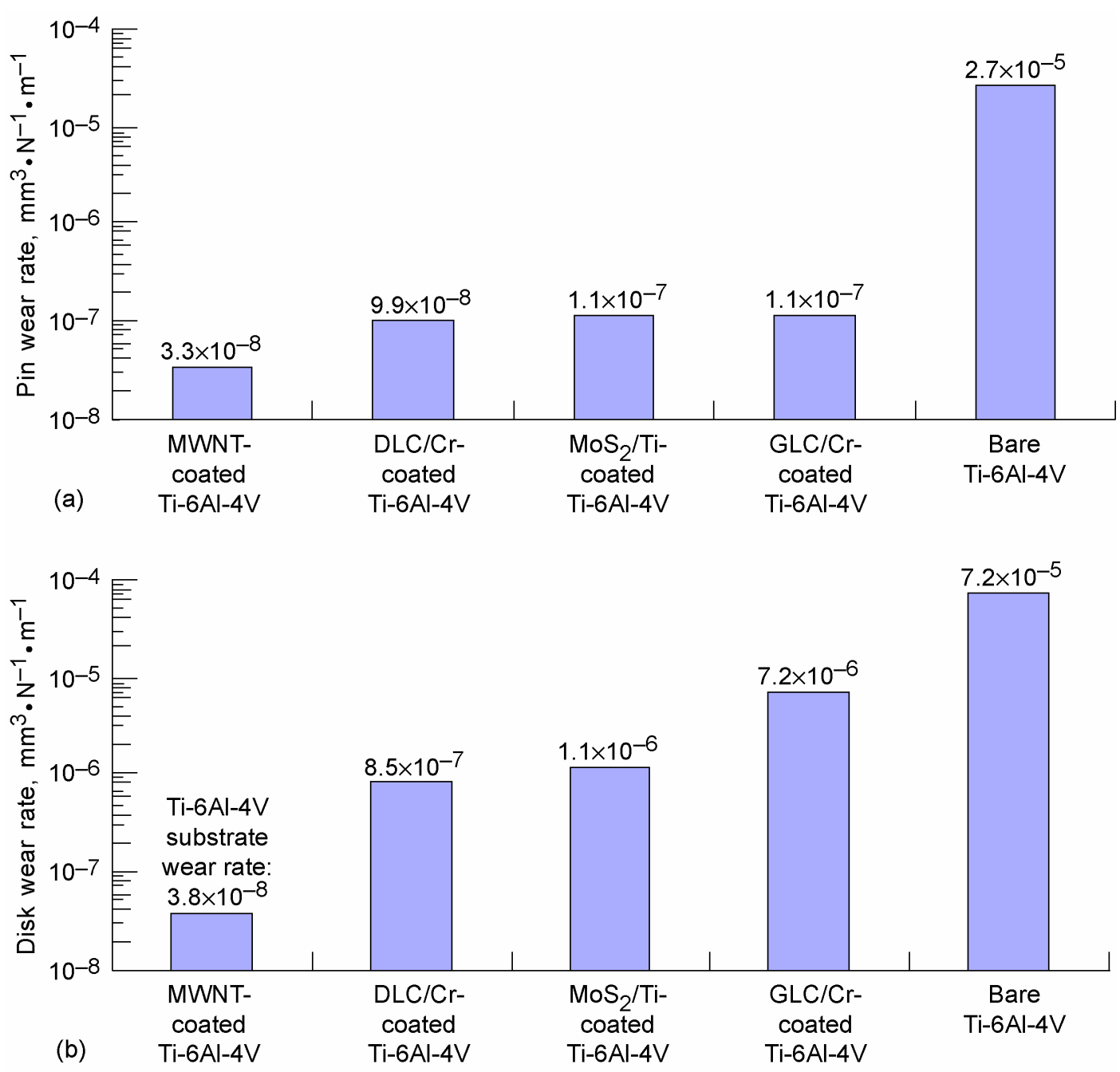

Figure 4.-Wear of bare $\mathrm{TiC} / \mathrm{Ti}-6 \mathrm{Al}-4 \mathrm{~V}$ pins in contact with different counterpart material disks: multiwalled nanotubes (MWNTs) on Ti-6Al-4V, DLC/Cr on Ti-6Al-4V, GLC/Cr on Ti-6Al-4V, $\mathrm{MoS}_{2} / \mathrm{Ti}$ on Ti-6AI-4V, and bare Ti-6Al-4V in air at $296 \mathrm{~K}$. (a) Wear of bare TiC/Ti-6Al-4V pins. (b) Wear of counterpart coatings on disks and of bare Ti-6Al-4V disks.

\section{TiC/Ti-6Al-4V Fretted Against Ti-48Al-2Cr-2Nb and Superalloy 718 With and Without MWNT Coating}

Figures 5(a) and (b) show the specific wear rates of pins and disks, respectively, obtained from fretting wear experiments with bare composite $\mathrm{TiC} / \mathrm{Ti}-6 \mathrm{Al}-4 \mathrm{~V}$ pins in contact with different counterpart material disks in air at $296 \mathrm{~K}$. Figure 5(a) indicates that the wear rates of pins for TiC/Ti-6Al-4V fretted against MWNTs deposited on Ti-48Al-2Cr-2Nb and on superalloy 718 are much lower than those for TiC/Ti-6Al-4V fretted against bare Ti-48Al-2Cr-2Nb and bare superalloy 718 . The MWNT coating reduced TiC/Ti-6Al-4V pin wear so much that it was almost not measurable (around $3.5 \times 10^{-8} \mathrm{~mm}^{3} \cdot \mathrm{N}^{-1} \cdot \mathrm{m}^{-} 1$; fig. $5(\mathrm{a})$ ).

The wear of the dispersed MWNT coating was difficult to define and was not measured in this investigation because of the nature of the tangled, dispersed MWNTs (fig. 2). Figure 5(b), therefore, presents the wear rate of the Ti-48Al-2Cr-2Nb and superalloy 718 substrates for MWNT-coated Ti-48Al$2 \mathrm{Cr}-2 \mathrm{Nb}$ and MWNT-coated superalloy 718 disks, respectively. The wear rates of uncoated, bare Ti$48 \mathrm{Al}-2 \mathrm{Cr}-2 \mathrm{Nb}$ and bare superalloy 718 disks are also shown in figure $5(\mathrm{~b})$. The wear rates shown in 

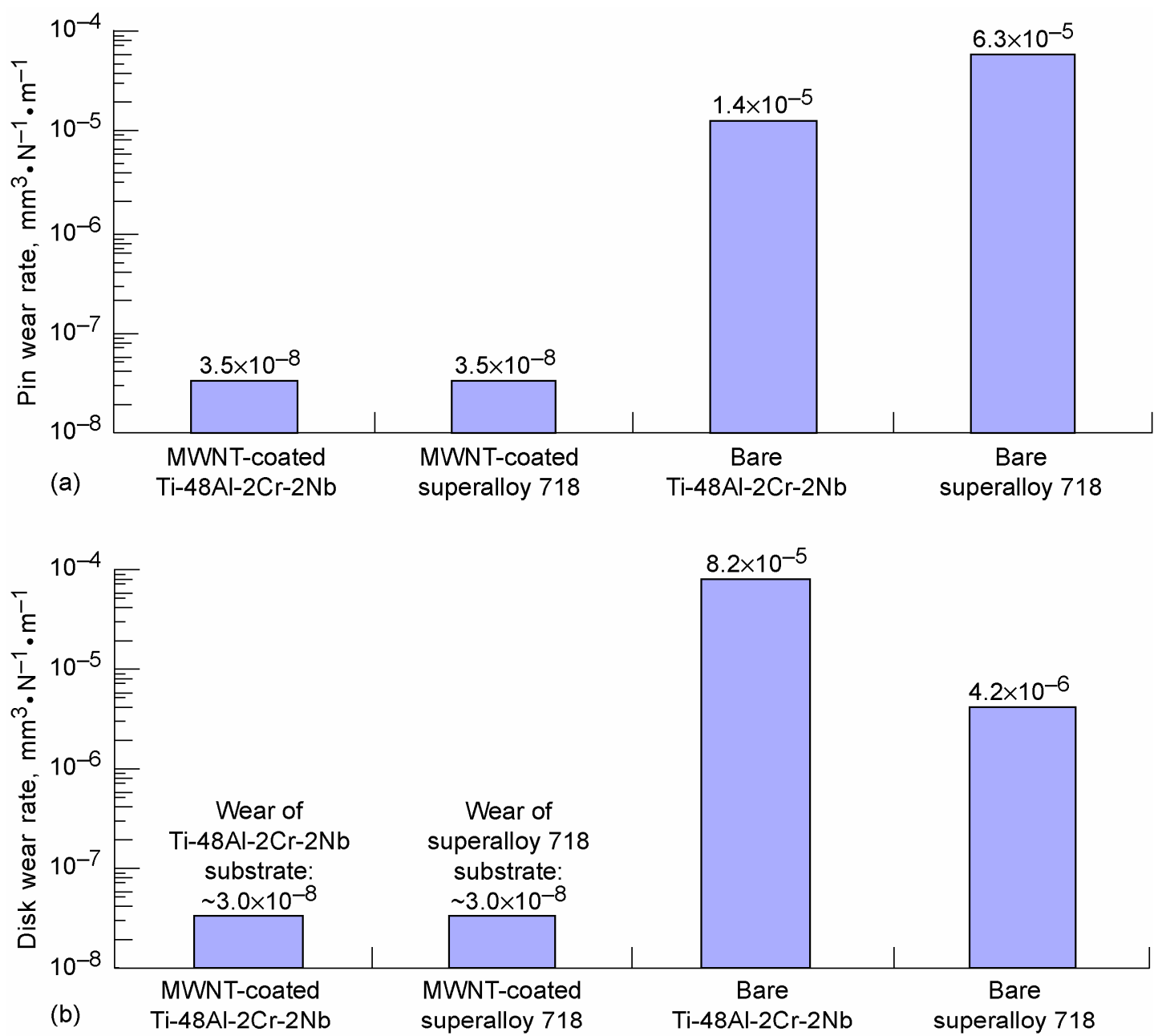

Figure 5.-Wear of bare TiC/Ti-6Al-4V pins in contact with different counterpart material disks: multiwalled nanotubes (MWNTs) on Ti-48Al-2Cr-2Nb, MWNTs on superalloy 718, bare Ti-48Al-2Cr-2Nb, and bare superalloy 718 in air at $296 \mathrm{~K}$. (a) Wear of bare TiC/Ti-6Al-4V pins. (b) Wear of counterpart MWNT-coated Ti-48AI-2Cr-2Nb and MWNT-coated superalloy 718 disk substrates and of bare Ti-48Al-2Cr-2Nb and bare superalloy 718 disks.

figure 5(b) should be viewed with caution. For MWNT-coated disks, almost no wear of the Ti-48Al-2Cr$2 \mathrm{Nb}$ and the superalloy 718 substrates was observed, and the wear rates were around $3 \times 10^{-8} \mathrm{~mm}^{3} \cdot \mathrm{N}^{-1} \cdot \mathrm{m}^{-1}$. In contrast, the wear rates of bare Ti-48Al-2Cr-2 Nb and bare superalloy 718 fretted against the TiC/Ti$6 \mathrm{Al}-4 \mathrm{~V}$ composite were $8.2 \times 10^{-5} \mathrm{~mm}^{3} \cdot \mathrm{N}^{-1} \cdot \mathrm{m}^{-1}$ and $4.2 \times 10^{-6} \mathrm{~mm}^{3} \cdot \mathrm{N}^{-1} \cdot \mathrm{m}^{-1}$, respectively.

\section{Wear at Elevated Temperatures}

Figures 6(a) and (b) show the effect of temperature on the specific wear rate of pins and disks, respectively, obtained from fretting wear experiments for bare composite TiC/Ti-6Al-4V pins in contact with different counterpart material disks in air at temperatures of 296, 423, and $523 \mathrm{~K}$. Figures 6(a) and (b) show that the wear rates of both the pins and disks for the composite TiC/Ti-6Al-4V fretted against the MWNT-, DLC/Cr-, GLC/Cr-, and $\mathrm{MoS}_{2} / \mathrm{Ti}$-coated Ti-6Al-4V disks increased as the temperature increased. In contrast, the wear rates of the pin and disk for the composite TiC/Ti-6Al-4V pin fretted against the bare Ti-6Al-4V disk were almost unchanged in the temperature range between 296 and $523 \mathrm{~K}$. The wear rates of the composite TiC/Ti-6Al-4V pins fretted against the MWNT-, DLC/Cr-, 

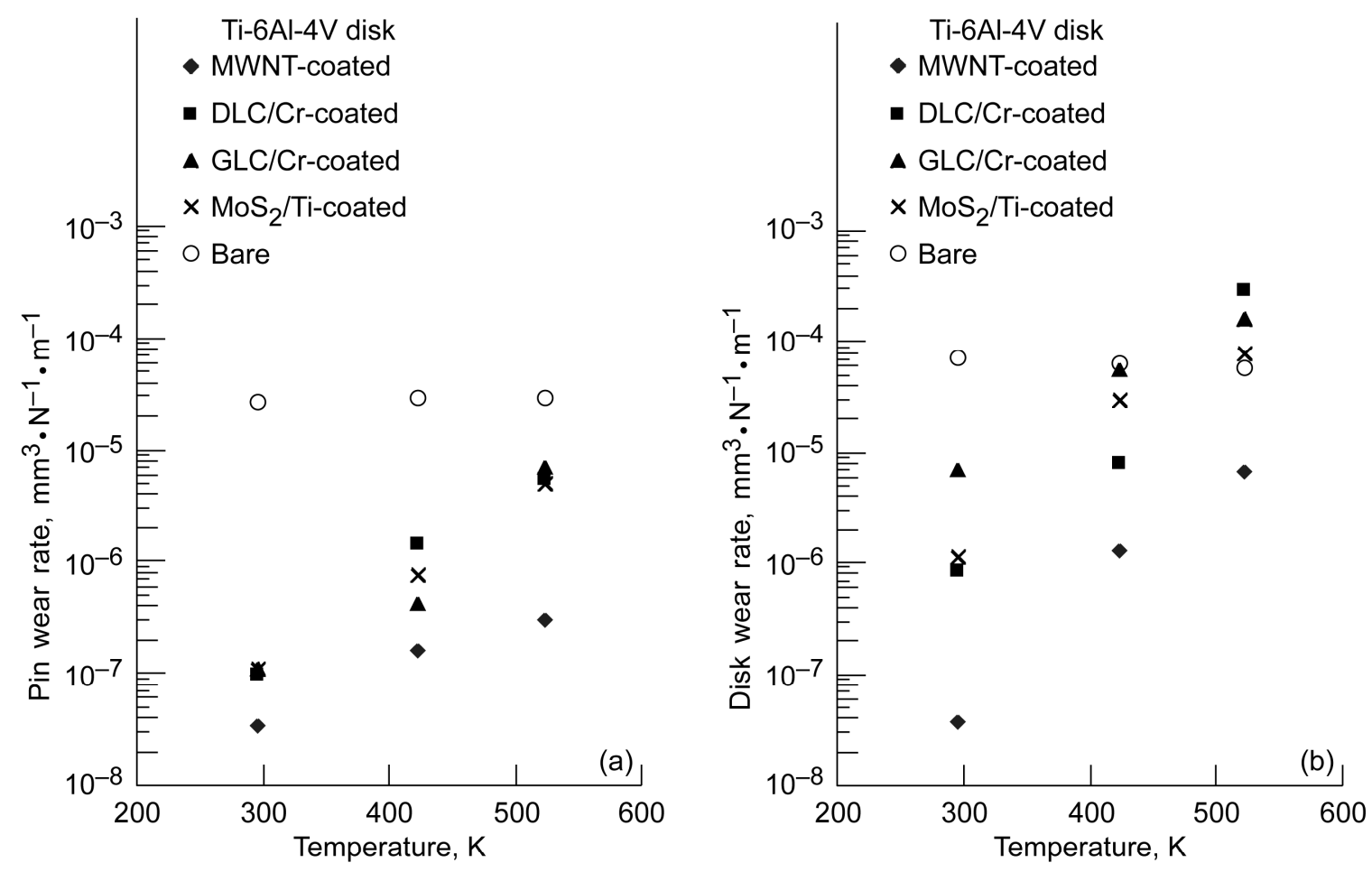

Figure 6.-Effect of temperature on fretting wear volume losses for bare TiC/Ti-6Al-4V pins in contact with different counterpart material disks: multiwalled nanotubes (MWNTs) on Ti-6Al-4V, DLC/Cr on Ti-6AI-4V, GLC/Cr on Ti-6Al-4V, MoS $_{2} / \mathrm{Ti}$ on Ti-6Al-4V, and bare Ti-6Al-4V in air at $296 \mathrm{~K}$. (a) Wear of bare TiC/Ti-6Al-4V pins. (b) Wear of counterpart coatings on disks and of bare Ti-6Al-4V disk.

GLC/Cr-, and $\mathrm{MoS}_{2} /$ Ti-coated Ti-6Al-4V disks at 423 and $523 \mathrm{~K}$ were lower than for the pin fretted against the bare Ti-6Al-4V disk. Although the wear rates of the MWNT-coated disks were still lower than that of the bare Ti-6Al-4V disk, the wear rates of the DLC/Cr-, GLC/Cr-, and $\mathrm{MoS}_{2} / \mathrm{Ti}$-coated Ti-6Al-4V disks exceeded that of the bare Ti-6Al-4V disk at $523 \mathrm{~K}$.

\section{Observations of Wear Debris}

As an example, figures 7(a) and (b) show a VSI surface profile of a bare, polished pin and that of a pin after fretting against a MWNT-coated Ti-6Al-4V disk, respectively. In contrast to figure 7(a), the twodimensional profile in figure 7(b) shows buildups of transferred MWNTs. SEM and optical microscopy indicated that the entire contact area of the counterpart TiC/Ti-6Al-4V pins fretted against MWNT coatings contained transferred agglomerated patches and particles of MWNTs. The contact area of the MWNT-coated Ti-6Al-4V disk still contained residual, smeared, agglomerated MWNT patches and particles in the contact area.

SEM observations for TiC/Ti-6Al-4V in contact with DLC/Cr-, GLC/Cr-, and $\mathrm{MoS}_{2} / \mathrm{Ti}$-coated Ti-6Al-4V disks indicated that regardless of the three types of solid-film lubricants, the surface damage on both the pin and disk at temperatures from 296 to $523 \mathrm{~K}$ consisted of submicrometer- and micrometersized wear debris particles all over the wear scars; a small amount of micrometer-sized, dislodged TiC wear debris; a few needlelike wear particles with diameters in the micrometer range and lengths in the tens-of-micrometers range; grooves formed in the slip direction where adhesion and subsequent shear fracture occurred; pits; craters; and cracks. Also, agglomerated wear debris particles in the ten- to thirtymicrometer range and agglomerated particles in the tens-of-micrometers range were found in and just 

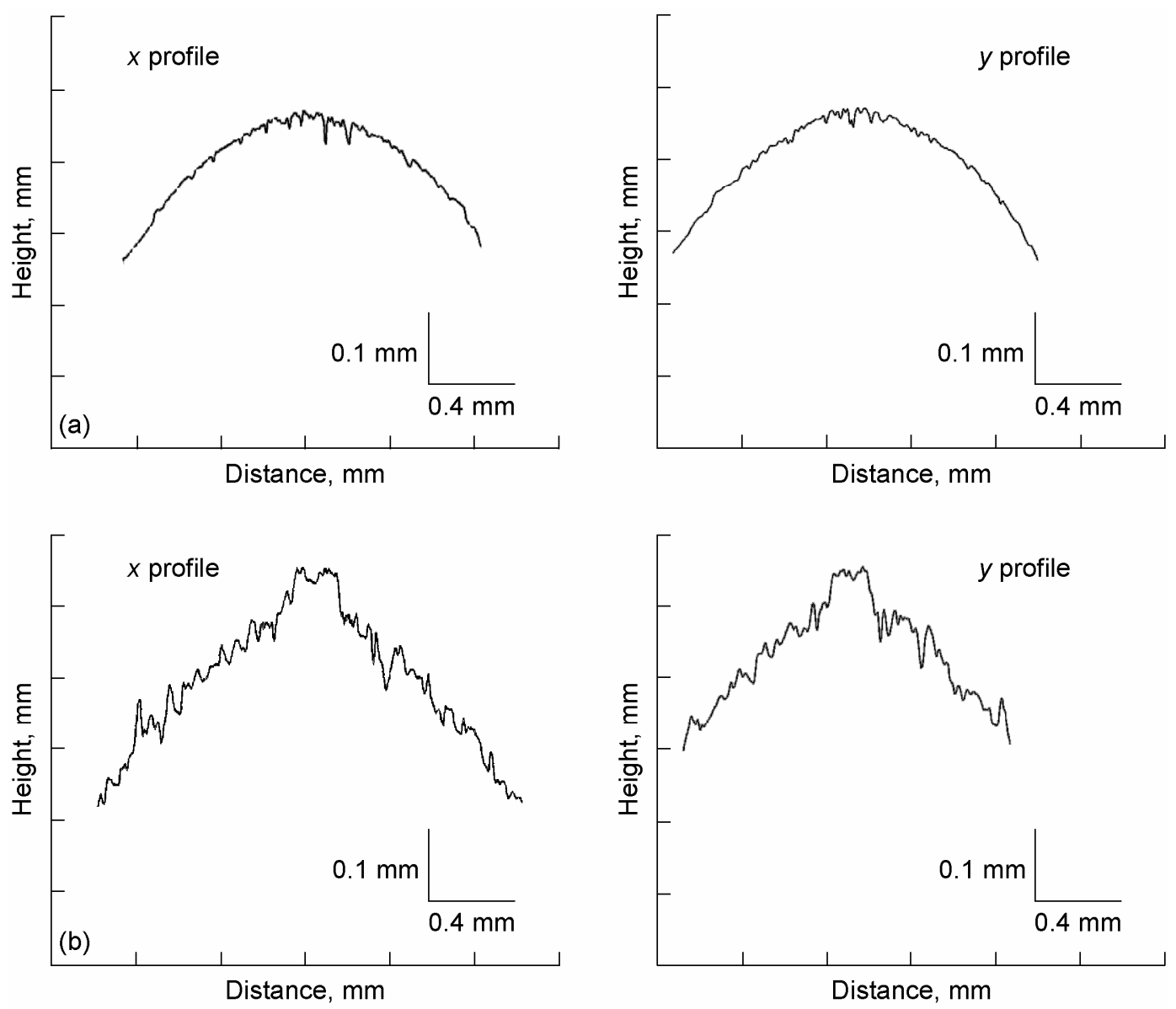

Figure 7.-Vertical-scanning-interferometry (VSI) surface profiles of TiC/Ti-6Al-4V pins. (a) Polished pin. (b) Pin fretted against multiwalled-nanotube- (MWNT-) coated Ti-6Al-4V disk.

outside of the wear scars, respectively. The surface damage on both the pin and disk generally increased at temperatures of 423 and $523 \mathrm{~K}$.

SEM observations for TiC/Ti-6Al-4V in contact with Ti-6Al-4V, Ti-48Al-2Cr-2Nb, and superalloy 718 in air at temperatures of 296,423 , and $523 \mathrm{~K}$ indicated that, regardless of the type of alloy, the surface damage on both the pin and disk consisted of alloy wear debris, alloy transfer, fracture pits, oxides and debris, scratches, craters and plastically deformed asperities, and cracks. Compared with specimens coated with the solid-film lubricants, the degree of the surface damage for these alloys was generally greater.

\section{Discussion}

\section{Effectiveness of MWNTs}

When an MWNT-coated Ti-6Al-4V substrate disk was brought into contact with a composite TiC/Ti-6Al-4V pin under fretting, strong bonds were formed between the MWNTs and the composite. The contact area of the composite TiC/Ti-6Al-4V pin was covered with transferred MWNTs, which prevented direct contact between the TiC/Ti-6Al-4V pin and the Ti-6Al-4V substrate. There was essentially no direct contact between the composite TiC/Ti-6Al-4V pin and the Ti-6Al-4V substrate disk when an MWNT coating was used. The MWNTs transferred to the pin and the MWNTs remaining on the disk protected both the pin and disk from wear. No galling occurred in the contacts during fretting. 
The wear behavior of TiC/T-6Al-4V in contact with MWNTs dispersed on both Ti-48Al-2Cr-2Nb and superalloy 718 was similar to that of the MWNTs dispersed on Ti-6Al-4V. There was no direct contact between the TiC/Ti-6Al-4V pin and Ti-48Al-2Cr-2Nb or superalloy 718 , and no galling occurred during fretting.

\section{Effectiveness of DLC/Cr, $\mathrm{MoS}_{2} / \mathrm{Ti}$, and GLC/Cr Coatings}

The surface characteristics of Ti-6Al-4V were much improved by the $\mathrm{DLC} / \mathrm{Cr}$, GLC/Cr, and $\mathrm{MoS}_{2} / \mathrm{Ti}$ coatings, enhancing the fretting wear resistance at room temperature $(296 \mathrm{~K})$. The effectiveness of a coating on fretting wear was the same regardless of the coating system. One was as good as another. The wear volume loss of TiC/T-6Al-4V in contact with $\mathrm{DLC} / \mathrm{Cr}-, \mathrm{MoS}_{2} / \mathrm{Ti}$-, and GLC/Cr-coating surfaces was 2 orders of magnitude lower than that of TiC/T-6Al-4V in contact with T-6Al-4V under fretting. Also, the wear volume losses of the DLC/Cr, $\mathrm{MoS}_{2} / \mathrm{Ti}$, and GLC/Cr coatings were 1 to nearly 2 orders of magnitude lower than that of Ti-6Al-4V. The wear volume losses of the composite TiC/Ti-6Al-4V fretted against DLC/Cr, GLC/Cr, and $\mathrm{MoS}_{2} / \mathrm{Ti}$ were on the order of $10^{-6} \mathrm{~mm}^{3}$, whereas those of the counterpart $\mathrm{DLC} / \mathrm{Cr}, \mathrm{GLC} / \mathrm{Cr}$, and $\mathrm{MoS}_{2} / \mathrm{Ti}$ were 1 order of magnitude greater than those of the composite (figs. 4(a) and (b)).

When the $\mathrm{DLC} / \mathrm{Cr}, \mathrm{MoS}_{2} / \mathrm{Ti}$, and $\mathrm{GLC} / \mathrm{Cr}$ coatings were applied to Ti-6Al-4V, direct contacts between TiC/T-6Al-4V and Ti-6Al-4V were avoided, and no galling occurred in the contacts during fretting. In contrast, when bare Ti-6Al-4V disks were brought into contact with TiC/T-6Al-4V pins, strong adhesion, severe galling, and severe fretting wear damage occurred in the contacts. The surfaces of TiC/T-6Al-4V and Ti-6Al-4V failed in tension and shear in the early stages of the fretting process because the interfacial adhesive bonds were stronger than the cohesive bonds in the alloys. Fractures in the TiC/T-6Al-4V and Ti-6Al-4V surfaces and in their oxide layers produced wear debris particles. The trapped wear debris at the interface caused abrasive wear, which is a severe form of wear. Similar behaviors were observed for the TiC/T-6Al-4V in contact with bare Ti-48Al-2Cr-2Nb and with superalloy 718 .

\section{Temperature Effects}

The wear rates obtained from the material couple of the composite $\mathrm{TiC} / \mathrm{Ti}-6 \mathrm{Al}-4 \mathrm{~V}$ and dispersed MWNTs deposited on Ti-6Al-4V were lower than those of the TiC/Ti-6Al-4V and Ti-6Al-4V couple in air at temperatures of 296, 423, and $523 \mathrm{~K}$. The MWNTs transferred to the pin and the MWNTs remaining on the disk protected both the composite TiC/Ti-6Al-4V pin and the Ti-6Al-4V substrate disk from wear regardless of the temperature, and no galling occurred in the contacts during fretting.

Temperature strongly influenced the wear behavior of the composite TiC/Ti-6Al-4V in contact with $\mathrm{DLC} / \mathrm{Cr}, \mathrm{GLC} / \mathrm{Cr}$, and $\mathrm{MoS}_{2} / \mathrm{Ti}$ coatings in relative motion under fretting. Temperature interacted with the fretting process in three ways: (1) The interactions at the contacting interface, such as adhesion, were temperature dependent and increased with an increase in temperature. (2) The mechanical and chemical properties of the coatings were temperature dependent and deteriorated with an increase in temperature. (3) The wear rates of both the composite and the coatings were temperature dependent and increased with an increase in temperature. The effectiveness of the $\mathrm{DLC} / \mathrm{Cr}, \mathrm{GLC} / \mathrm{Cr}$, and $\mathrm{MoS}_{2} / \mathrm{Ti}$ coatings on wear varied markedly with temperature and decreased as temperature increased. The wear rate of the $\mathrm{DLC} / \mathrm{Cr}$, $\mathrm{GLC} / \mathrm{Cr}$, and $\mathrm{MoS}_{2} / \mathrm{Ti}$ coatings exceeded that of the bare Ti-6Al-4V at $523 \mathrm{~K}$. Thus, even at elevated temperatures, there is an advantage in applying a MWNT coating to Ti-6Al-4V, but there is no advantage to using DLC/Cr, GLC/Cr, and $\mathrm{MoS}_{2} / \mathrm{Ti}$ coatings on Ti-6Al-4V in a high-temperature environment, particularly at $523 \mathrm{~K}$ and above. 


\section{Conclusions}

The following conclusions were drawn from studies of the fretting wear behavior of low-cost, lightweight $10-\mathrm{wt} \% \mathrm{TiC} / \mathrm{Ti}-6 \mathrm{Al}-4 \mathrm{~V}$ composite in contact with four types of solid-film lubricant coatings (MWNTs dispersed on Ti-6Al-4V, DLC/Cr deposited on Ti-6Al-4V, GLC/Cr deposited on Ti-6Al-4V, and $\mathrm{MoS}_{2} / \mathrm{Ti}$ deposited on Ti-6Al-4V) and with bare Ti-6Al-4V in air at temperatures of 296, 423, and $523 \mathrm{~K}$. In addition, the wear of TiC/Ti-6Al-4V in contact with MWNTs dispersed on Ti-48Al-2Cr-2Nb, with MWNTs on nickel-based superalloy 718, with bare Ti-48Al-2Cr-2Nb, and with bare nickel-based superalloy 718 was examined under fretting in air at $296 \mathrm{~K}$.

When TiC/Ti-6Al-4V was brought into contact with bare Ti-6Al-4V, bare Ti-48Al-2Cr-2Nb, and bare nickel-based superalloy 718 counterpart materials, strong adhesion, severe galling, and severe wear occurred under fretting in air. However, when TiC/Ti-6Al-4V was brought into contact with MWNT, $\mathrm{DLC} / \mathrm{Cr}, \mathrm{GLC} / \mathrm{Cr}$, and $\mathrm{MoS}_{2} / \mathrm{Ti}$ coatings, no galling occurred in the contact, and relatively minor wear was observed during fretting regardless of the coatings. For example, the wear rate of the composite $\mathrm{TiC} / \mathrm{Ti}-6 \mathrm{Al}-4 \mathrm{~V}$ fretted against MWNTs, DLC/Cr, GLC/Cr, and $\mathrm{MoS}_{2} / \mathrm{Ti}$ on Ti-6Al-4V was orders of magnitude lower than that fretted against bare Ti-6Al-4V in air at $296 \mathrm{~K}$.

All the solid-film lubricants are effective and are suitable for antigalling applications at temperatures from 296 to $523 \mathrm{~K}$ under fretting conditions. The MWNT coating remained effective in antiwear even at temperatures of 423 and $523 \mathrm{~K}$. In contrast, the wear resistance of all the coatings decreased as temperature increased.

\section{References}

1. Miyoshi, Kazuhisa: Solid Lubrication Fundamentals and Applications. Marcel Dekker, New York, NY, 2001.

2. VanStone, R.H.; Lawless, B.H.; and Hartle, M.: Fretting in Ti-6Al-4V at Room Temperature. Proceedings of the 5th National Turbine Engine High Cycle Fatigue (HCF) Conference, session 4, paper 1, 2000.

3. Chakravarty, S., et al.: The Effect of Surface Modification on Fretting Fatigue in Ti Alloy TurbineComponents. JOM, vol. 47, no. 4, 1995, pp. 31-35.

4. Hoeppner, David; Adibnazari, Saeed; and Moesser, Mark W.: Literature Review and Preliminary Studies of Fretting and Fretting Fatigue Including Special Applications to Aircraft Joints; Final Report. DOT/FAA/CT-93/2, 1994.

5. Hutson, A.L.; and Nicholas, T.: Fretting Fatigue Behavior of Ti-6A1-4V Against Ti-6Al-4V Under Flat-on-Flat Contact With Blending Radii. ASTM STP-1367, 2000, pp. 308-321.

6. Miyoshi, K., et al.: Sliding Wear and Fretting Wear of Diamondlike Carbon-Based, Functionally Graded Nanocomposite Coatings. Wear, vols. 225-229, no. 1, 1999, pp. 65-73.

7. Miyoshi, Kazuhisa, et al.: Evaluation of Ti-48Al-2Cr-2Nb Under Fretting Conditions. NASA/TM-2001-211205, 2001.

8. Miyoshi, Kazuhisa; Lerch, Bradley A.; and Draper, Susan L.: Preliminary Study on Fatigue Strengths of Fretted Ti-48Al-2Cr-2Nb. NASA/TM-2002-211718, 2002.

9. Miyoshi, et al.: Ti-48Al-2Cr-2Nb Evaluated Under Fretting Conditions. Research and Technology 2001, NASA/TM-2002-211333, 2002.

10. Miyoshi, Kazuhisa; Lerch, Bradley A.; and Draper, Susan L.: Fretting Wear of Ti-48Al-2Cr-2Nb. Tribol. Int., vol. 36, no. 2, 2003, pp. 145-153.

11. Miyoshi, Kazuhisa; Lerch, Bradley A.; and Draper, Susan L.: Foreword. Tribol. Int., vol. 36, 2003, p. 69.

12. Miyoshi, Kazuhisa, et al.: Evaluation of Ti-48Al-2Cr-2Nb Under Fretting Conditions. ASTM STP-1425, 2002, pp. 323-337. 
13. Abkowitz, Stanley, et al.: Commercial Application of Low-Cost Titanium Composites. JOM, vol. 47, no. 8,1995 , pp. 40-41.

14. U.S. Government Printing Office: Advanced Materials by Design. OTA-E-351, 1988, p. 335.

15. Materials Science and Engineering: Forging Stronger Links to Users. National Materials Advisory Board Publication 492, 1999.

16. Lerch, Bradley A; Ellis, J. Rodney; and Arnold, Steven M.: Particulate Titanium Matrix Composites Tested-Show Promise for Space Propulsion Applications. Research and Technology 2003, NASA/TM-2004-212729, 2004, pp. 156-157.

17. Miyoshi, K., et al.: Solid Lubrication by Multiwalled Carbon Nanotubes in Air and in Vacuum. Tribol. Lett., vol. 19, no. 3, 2005, pp. 191-201.

18. MoST Coatings, Graphit-iC Coatings, and Dymon-iC Coatings. Teer Coatings Ltd. http://www.teercoatings.co.uk/ Accessed Nov. 10, 2006.

19. Miyoshi, K.: Surface Analysis and Tools. Tribology of Mechanical Systems, J. Vizintin, et al., eds., ASME Press, New York, NY, 2004, pp. 293-312.

20. Miyoshi, K.: Surface Characterization Techniques: An Overview. Mechanical Tribology: Materials, Characterization, and Applications. George E. Totten and Hong Liang, eds., pt. 2, Marcel Dekker, New York, NY, 2004, pp. 33-56. 


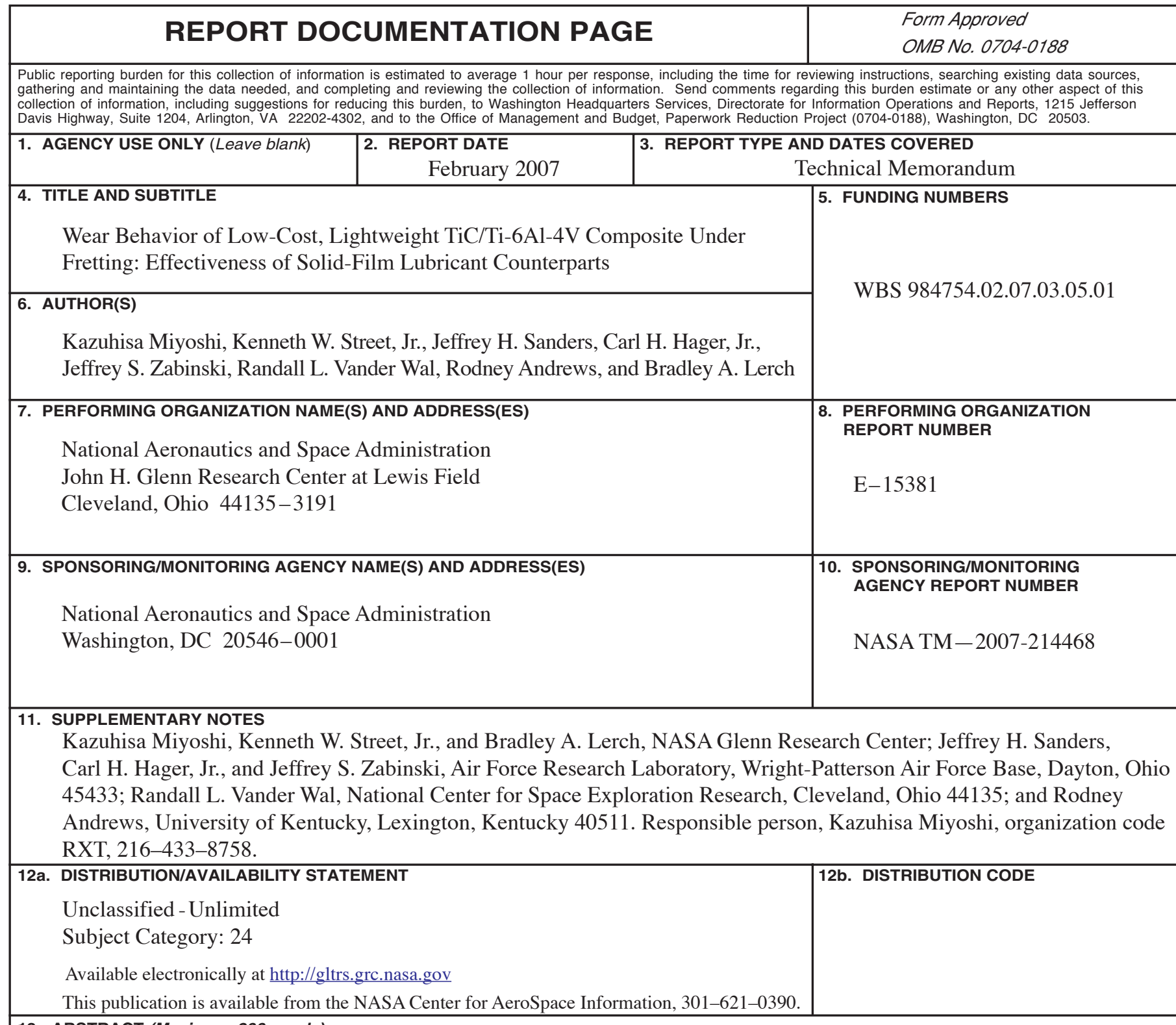

13. ABSTRACT (Maximum 200 words)

The wear behavior of low-cost, lightweight 10-wt\% TiC-particulate-reinforced Ti-6Al-4V matrix composite (TiC/Ti$6 \mathrm{Al}-4 \mathrm{~V}$ ) was examined under fretting at 296, 423, and $523 \mathrm{~K}$ in air. Bare 10-wt\% TiC/Ti-6Al-4V hemispherical pins were used in contact with dispersed multiwalled carbon nanotubes (MWNTs), magnetron-sputtered diamondlike carbon/chromium (DLC/Cr), magnetron-sputtered graphitelike carbon/chromium (GLC/Cr), and magnetron-sputtered molybdenum disulphide/titanium $\left(\mathrm{MoS}_{2} / \mathrm{Ti}\right)$ deposited on Ti-6Al-4V, Ti-48Al-2Cr-2Nb, and nickel-based superalloy 718. When TiC/Ti-6Al-4V was brought into contact with bare Ti-6Al-4V, bare Ti-48Al-2Cr-2Nb, and bare nickelbased superalloy 718, strong adhesion, severe galling, and severe wear occurred. However, when TiC/Ti-6Al-4V was brought into contact with MWNT, DLC/Cr, GLC/Cr, and $\mathrm{MoS}_{2} / \mathrm{Ti}$ coatings, no galling occurred in the contact, and relatively minor wear was observed regardless of the coating. All the solid-film lubricants were effective from 296 to $523 \mathrm{~K}$, but the effectiveness of the MWNT, DLC/Cr, GLC/Cr, and $\mathrm{MoS}_{2} / \mathrm{Ti}$ coatings decreased as temperature increased.

\begin{tabular}{|c|c|c|}
\hline \multicolumn{3}{|l|}{$\begin{array}{l}\text { 14. SUBJECT TERMS } \\
\text { Fretting; Particulate reinf } \\
\text { Metal matrix composites }\end{array}$} \\
\hline $\begin{array}{l}\text { 17. SECURITY CLASSIFICATION } \\
\text { OF REPORT } \\
\text { Unclassified }\end{array}$ & $\begin{array}{l}\text { 18. SECURITY CLASSIFICATION } \\
\text { OF THIS PAGE }\end{array}$ & $\begin{array}{l}\text { 19. SECURITY CLASSIFICATION } \\
\text { OF ABSTRACT }\end{array}$ \\
\hline Unclassified & Unclassified & Unclassified \\
\hline
\end{tabular}



